Health Place. 2011 July ; 17(4): 978-987. doi:10.1016/j.healthplace.2011.03.009.

\title{
Allostatic Load in an Environmental Riskscape: The Role of Stressors and Gender
}

\author{
Christine A. Maira, Malcolm P. Cutchin ${ }^{\mathrm{b}}$, and M. Kristen Peek ${ }^{\mathrm{c}}$ \\ aDepartment of Sociology and Anthropology, University of Maryland, Baltimore County, 1000 \\ Hilltop Circle, Baltimore, MD 21250-0002 \\ bDepartment of Allied Health Sciences, University of North Carolina, CB \#7122, Bondurant Hall, \\ Suite 2050, Chapel Hill, NC 27599-7122 \\ 'Department of Preventive Medicine and Community Health, University of Texas Medical Branch, \\ 301 University Blvd, Galveston, TX 77555-1153
}

\begin{abstract}
Stressors are theorized to be associated with higher allostatic load (AL), a concept of physiological wear measured as a composite of physical biomarkers. Risk of high AL may vary by gender and may be intensified in places with significant environmental risks, otherwise known as 'environmental riskscapes'. Yet, no study has examined the relationship between stressors, gender, and allostatic load in an environmental riskscape. Using primary data collected in a sample $(\mathrm{N}=1072)$ exposed to various environmental and social stressors, we find that long-term residence in Texas City (more than 30 years), residential proximity to petrochemical plants, perceived poor neighborhood conditions, and daily hassles are associated with higher allostatic load components. Variation in AL differs by gender and the types of biomarkers examined. Gender moderates the effect of length of residence in Texas City on cardiovascular health risk. We discuss our findings in light of current research on stressors, gender, allostatic load, and double jeopardy within environmental riskscapes.
\end{abstract}

\section{Keywords}

allostatic load; stressors; gender; environmental riskscapes; health disparities

\section{Introduction}

Conceptually, allostatic load (AL) refers to the body's ability to adjust physiologically to stressors. Operationalized as a measure of physiological homeostasis (Sterling and Eyer, 1988), AL is measured through a diverse set of biomarkers collected from blood, saliva, and other clinical means that reflect cardiovascular, metabolic, inflammatory, neuroendocrine, and immune-related risk (McEwen, 1998; McEwen and Seeman, 1999; Seeman et al., 2001). As the body adapts to its environment, it undergoes "wear and tear" that can accumulate, leading to systemic dysregulation manifested as higher AL (Dowd et al., 2009; Ganzel et al., 2010; Glei et al., 2007; Seeman et al., 1997). Although women report more stressors and

\footnotetext{
(C) 2011 Elsevier Ltd. All rights reserved.
}

Publisher's Disclaimer: This is a PDF file of an unedited manuscript that has been accepted for publication. As a service to our customers we are providing this early version of the manuscript. The manuscript will undergo copyediting, typesetting, and review of the resulting proof before it is published in its final citable form. Please note that during the production process errors may be discovered which could affect the content, and all legal disclaimers that apply to the journal pertain. 
higher perceived stress, no study has examined the relationship between stressors, gender, and AL. Further, we know little about how stressors and gender shape AL within an environmental riskscape - such as an area with substantial environmental health risks or poor neighborhood conditions (Morello-Frosch and Shenassa, 2006; Simandan, 2010). Thus, this study is one of the first to assess the relationship between stressors, gender, and AL in the context of an environmental riskscape. After describing further context for the study, methods, and findings, we discuss how our study supports a new understanding of the mechanisms that contribute to health disparity.

\section{Stress Processes and Allostatic Load Risk}

Stressful environments get "under the skin" to cause health problems (Taylor et al., 1997), yet there is still much unknown about how that process may work and how particular exposure to contextual conditions may shape the process. Chronic and acute exposure to stressors may yield long-term health consequences (Ganzel et al., 2010; McEwen, 1998). Stressors are theorized to be associated with neuroendocrine responses, which can have cascading effects on other systems of the body by increasing blood pressure, immuneresponses, cancer, etc. (McEwen, 1998; Taylor et al., 1997). Theoretically, stressors such as dangerous situations, social instability, living in an "unpleasant neighborhood," negative life events, and daily hassles may be linked to elevated allostatic load (McEwen, 1998; McEwen and Seeman, 1999). In addition, health disparities literature posits gender differences in the stress process. Thus, there may be gender differences in AL and its components as well as gender differences in the association between stressors and AL.

In terms of the physical environment, stressors such as environmental hazards or poorquality built environments, may be chronic or acute and are theoretically linked to poor health (Cutchin, 2007; Hill et al., 2009; Pearlin et al., 2005; Stronegger at al., 2010). Specifically, living in close proximity to an environmental hazard or having a high level of perceived exposure to environmental threats is associated with increased stress (Burby and Strong, 1997; Hallman and Wandersman, 1992; Luginaah et al., 2000; Yang and Matthews, 2010). Stress resulting from these types of environmental stressors may be associated with negative physiological outcomes. For example, a study of Three Mile Island in Pennsylvania finds elevated physiological risk factors, such as lower lymphocytes, higher cortisol, and higher levels of herpes simplex reactivation among residents living near the damaged nuclear reactor (McKinnon et al., 1989). In addition to environmental hazards, neighborhood conditions may operate as stressors. Evans (2003) reports that physical aspects of the neighborhood (household crowding, quality) are associated with elevated AL among rural children. These studies provide preliminary empirical evidence of a link between environmental stressors and risk of elevated AL. Yet, it is unknown if exposure to environmental hazards, perceived risk from those hazards, or poor quality neighborhoods are associated with elevated AL.

Stressors that are more psychosocial in origin—such as negative life events (e.g., divorce or death of a loved one) and daily hassles (e.g., family or financial worries) - are also theorized to be associated with AL (McEwen, 1998). Yet, the few studies to test the relationship between negative life events and AL or physiological dysregulation find little to no association (Clark et al., 2007; Glei et al., 2007). Further, no study has tested the link between daily hassles and AL. Daily hassles are weakly associated with poor immune flexibility (Peters et al., 2003), chest pain (Lau et al., 1996), and outpatient health care utilization (Williams et al., 1992) —all of which may indirectly reflect physiological dysregulation.

In addition to stressors per se, clinical classifications of high risk AL differ for men and women (Seeman et al., 2002), although no studies examine gender differences in stressors 
and AL. Women are typically classified as a disadvantaged group, yet this disadvantage does not always translate into poorer health (Macintyre et al., 1996; Rieker and Bird, 2005). Theoretical examinations of gender health disparities suggest that differences in the effects of stressors may not necessarily indicate that men and women are differentially susceptible to stressors (Aneshensel et al., 1991). Women may have more exposure to stressors (Rieker and Bird, 2005). Indeed, women report more negative life events (Turner and Avison, 2003) and higher stress levels (McDonough and Walters, 2001). However, some studies find that stressor exposure does not account for gender differences (McDonough and Walters, 2001; Turner and Avison, 2003). A study exploring concern over environmental risk reports that women have higher concern about risk than men in high quality neighborhoods but not in "stressed" neighborhoods (Greenberg and Schneider, 1995). Few studies, however, examine gender differences in the relationship between stressors and health in environmental riskscapes. Thus, it is unknown whether stressful environments get "under the skin" more for women than for men.

\section{Stressors and Allostatic Load in Environmental Riskscapes}

Overlapping risk factors may leave individuals vulnerable to double jeopardy. MorelloFrosch and Shenassa (2006) incorporate the concept of double jeopardy in a manner than considers local context and AL. The authors propose a framework that incorporates built environment, social environment, and psychosocial stressors as fundamental risks associated with allostatic load. They suggest that the combination of community-level and individuallevel stressors creates a unique form of double jeopardy that can lead to health disparities, particularly among already disadvantaged groups such as women. This 'riskscape' framework explicitly suggests a strong relationship between place and physiological wear, as indicated by A. What the literature lacks, however, are studies that combine various community and individual-level measures of stressors together with gender to better understand place-based jeopardy for higher allostatic load.

Although the environmental riskscape is "driven by the distribution of power, privilege and economic resources" (Morello-Frosch and Shenassa, 2006, p. 1152), Morello-Frosch and Shenassa do not suggest processes that shape such distributions in particular places or identify analytical perspectives through which to recognize them. In contrast, Cutchin (2007) argues that there are several intertwined geographical processes at work in such risky and unequal places. Specifically, he describes historical and cultural processes materialized in the landscape of Texas City, Texas as a way to illuminate the agents and power that create unequal risk. Cutchin (2007) also invokes political ecology and territoriality perspectives to understand the intertwined local, state, national, and global scale processes that emerge in the local landscape and neighborhoods of Texas City. Those processes differentiate the risk experienced by various groups in Texas City. Other work by Cutchin and colleagues (2008) argues that at a smaller scale, the transactional process of stress and coping, theorized by Lazarus (1991; 1999), is relevant to understanding risky environments and individuals' relationship with them-a relationship that, in turn, influences health.

By taking these perspectives as a group and integrating them with allostatic load theory, we can begin to more thoroughly theorize an important health process-stressor exposure and the bodily response to it. The benefit of this approach is that it allows us to analytically combine processes at various scales of analysis. Therefore, these processes can be considered either upstream (more distal) or direct (more proximal) causes of AL and the poor health it indicates. Broader scale foci, such as the global reach and power of oil corporations, go well beyond the meso-scale conceptualizations of Ganzel et al., (2010) and Morello-Frosch and Shenassa (2006). Yet, those meso-scale understandings are essential to understand risk and health in particular places, particularly when combined with transactional stress and coping theory. Allostatic load theory completes the picture. The 
allostatic load perspective implicates specific physiological processes that reflect individuals' exposures and experiences within those broader geographical scales. This theoretical integration of allostatic load and geographical theory marks an initial step toward Simandan's (2010) recent call for allostatic load research that would unify explanation across geographical scales, ranging from the body to the global political economy. Moreover, this combined perspective stretches the understanding of a riskscape to encompass a broader range of processes. Although not all components of this integrated view can be included in this study, an awareness of a more holistic geographical understanding of process, place, and health facilitates an enhanced position for inference and explanation.

\section{Hypotheses}

In accordance with the allostatic load and health geography literature, we hypothesized that stressors are associated with higher overall AL and AL components. Drawing from gender and health literature, we hypothesized that the predictive power of stressors varies by gender and by the type of allostatic outcome examined. Finally, we hypothesized that gender moderates the relationship between stressors and AL, suggesting different processes by gender.

\section{Data and Methods}

\section{Data}

We analyzed data from the Texas City Stress and Health Study collected between 2004 and 2006 in Texas City, Texas, a small urban setting in close proximity to a large complex of petrochemical plants (Cutchin, 2007; Cutchin et al., 2008; Meyler et al., 2007; Peek et al., 2008; Peek at al., 2009a). The dataset was designed to study sociobiological stress and health in a representative sample of individuals from multiple ethnic/race groups $(\mathrm{N}=2706)$. These data are particularly suited to the study of stressors, gender, and AL for two primary reasons. First, this dataset contains an unusually diverse collection of stressor measures. Second, the study collected numerous AL biomarkers from a large subsample of respondents $(\mathrm{N}=1457)$.

Texas City residents were surveyed in three stages: (a) All households in a 12 mile $^{2}$ area near the oil refineries were contacted and classified into three groups (Hispanics 25-64 years, Hispanics 65+ years, and non-Hispanics); (b) Each Hispanic household and 1/8 of all non-Hispanic households were selected; (c) Of Hispanics 25-64 years and non-Hispanics, one adult in each household was randomly selected as eligible for interview and all Hispanics aged $65+$ were deemed eligible for interview. This sampling design yielded three strata: (a) 1/8 of all non-Hispanic households; (b) a majority of Hispanic households with one respondent aged 25-64; and (c) a full census of Hispanics aged 65+ from the study area. Households with at least one Hispanic adult present were classified as "Hispanic".

The study utilized U.S. Census Bureau Current Population Survey methods for listing, enumeration, and interviewing-yielding a response rate of 80 percent. Respondents were asked to provide a blood sample and 54 percent $(\mathrm{N}=1457)$ complied. A trained phlebotomist drew blood in a clinic or in the subject's home between 8 and $11 \mathrm{AM}$ after fasting. Blood samples were centrifuged to obtain plasma, which was stored at $-70^{\circ} \mathrm{C}$ until testing. Plasma levels of IL-6, IL-10, CRP, and TNF-alpha were analyzed using standard ELISA methods. Samples were batch analyzed to minimize interassay variation. Anti-viral antibody titers were determined by indirect immunofluorescence (Stowe et al., 2001; Tingate et al., 1997). Commercially-prepared substrate slides and control sera (Microgen Laboratories, La Marque, TX, and Bion Enterprises, Park Ridge, IL) were used for determining antibody 
titers to EBV-VCA, EBV-EA, EBNA, and HSV-1. All specimens were batch analyzed and read blind-coded. Detailed information on the blood collection protocol is available elsewhere (Peek et al., 2009a, 2009b; Stowe et al., 2010a, 2010b). The institutional review board at University of Texas Medical Branch approved the study protocol, and informed consent was obtained from all participants.

Because the "other" race/ethnicity category composed a small proportion of the biomarker subsample $(\mathrm{N}=15)$ and because Hispanics not of Mexican origin in the subsample were a diverse group ( $\mathrm{N}=82)$, we excluded those individuals. From this biomarker subsample, we included cases with full data on all 16 biomarkers $(\mathrm{N}=1192)$. After listwise deletion, our analytical sample included 1072 respondents.

\section{Measures}

Dependent variables included total allostatic load and four components of AL (cardiovascular, metabolic, inflammatory, and immune-related; see Table 1). Traditional composite measures of AL identify "high risk" cut-offs for each biomarker and sum the resulting binary scores, similar to a checklist. This approach, however, reduces variation and may not capture the full range of AL (Loucks et al., 2008). Therefore, we opted for a z-score measure of AL to utilize the interval scores and their variation. Results from this z-scored summation variable creation method did not differ significantly from results using the dichotomous summation method. Before stratifying the sample by gender, we constructed $\mathrm{z}$ scores (mean $=0$, S.D. $=1$ ) for each of the 16 biomarkers. We then created a summation score for total AL as well as cardiovascular, metabolic, inflammatory, and immune-related components of AL.

Consistent with previous studies, we included age, age squared, and race/ethnicity in our models (Crimmins et al., 2003; Geronimus et al., 2006). For specific operationalization of variables, see Table 1. Age was a continuous variable. We constructed an age squared term to account for non-linear effects. Race/ethnicity was derived from self-identified race/ ethnicity and nativity status. Our analysis included non-Hispanic Whites, non-Hispanic Blacks and individuals of Mexican origin. For individuals of Mexican origin, we distinguish between "foreign-born" and "US-born" (Crimmins et al., 2007; Kaestner et al., 2009; Peek et al., 2009b).

Our key independent variables were gender and stressors. Because thresholds of biomarker "high risk" differ by gender, we controlled for gender in analyses of the total sample ( $1=$ female) and also stratified the sample by gender. Measures of stressors included exposure to petrochemical plants, concern about petrochemical health risks, neighborhood perception, negative life events, and daily hassles. Exposure to the plants was measured by two variables: length of time residing in Texas City and residential distance from the petrochemical plants' fence line in meters. Because our theoretical scope includes an interest in chronic, long-term environmental stressors and to be consistent with previous literature (Cutchin et al., 2008), we categorized length of residence in Texas City as less than 15 years, 15 to 30 years, and more than 30 years (reference category=less than 15 years). Concern about petrochemical health risk (CAPHRS; Cutchin et al., 2008) was a summation score of four items measuring respondents' subjective assessments of exposure concern. Neighborhood perception was measured with the perceived neighborhood scale, which included subscales for social embeddedness, sense of community, satisfaction with neighborhood, and perceived crime (Martinez et al., 2002). Higher neighborhood perception scores indicate a more positive perception. Negative life events were measured by 27 items to indicate whether or not respondents or an immediate family member experienced negative life events (such as injuries, accidents, deaths, crime, family issues, and financial/job/school troubles) in the past year (Turner et al., 1995). Higher scores indicate more negative life 
events. Daily hassles were measured as a summation score of 18 items on a scale of 0 to 3 , which asked respondents how bothered they were by responsibilities, time/money constraints, family/friend issues, and neighborhood/environment concerns. Increasing values indicate more daily hassles (Kanner et al., 1981).

We also included the following potential confounding factors: married; Medical Outcomes Study (MOS) Social Support Scale (Sherbourne and Stewart, 1991); high school degree; income; smoking and exercise behaviors; perceived stress (Cohen and Williamson, 1988); sum of chronic health conditions; and health insurance status (Table 1).

\section{Analysis}

We began our analysis by addressing missing data. Missing data on neighborhood perception items ranged from 0.7 percent $(\mathrm{N}=20)$ to 8 percent $(\mathrm{N}=202)$. Summing these items yielded 22 percent of cases with at least one missing item for the scale $(\mathrm{N}=604)$. Income contained 11 percent missing cases $(\mathrm{N}=296)$. Missing data analysis determined that these items were missing at random. Therefore, we imputed these measures with an EM estimation algorithm (PSAW 18; Garson, 2008). In addition, we removed eight items from the daily hassles scale and two from the negative life events scale due to missing data. In both cases, removing these items reduced missing data and improved reliability estimates (Cronbach's alpha). We also conducted multivariate outlier analysis and identified 11 outliers. Because sensitivity tests determined that these outliers did not change the results, these cases were not removed.

All analyses were performed for the total sample, for men, and for women. We conducted descriptive analysis (Table 2) and ordinal least squares (OLS) regression analysis (Tables 3 and 4). For OLS models predicting total AL, Model 1 included sociodemographic variables: age, age squared, and race/ethnicity, and female (for the total sample). Model 2 added stressors to the model and Model 3 added all control variables. Model 3 (full model) was used in analyses predicting components of AL (Table 4). Models predicting the inflammatory component were not statistically significant as a whole and thus are not presented in Table 4. To examine the potential moderating effect of gender, we tested interaction effects between gender and stressors for AL and its subcomponents (Newsom et al., 2003). Because there was a statistically significant interaction between gender and a key stressor measure (residing in Texas City for more than 30 years) when predicting cardiovascular AL, we present all results for the total sample, as well as stratified by gender in order to explore the explanatory power of stressors and the role of Texas City residence for women and men separately.

\section{Results}

Descriptive statistics revealed differences in AL and stressors by gender (Table 2). Men had higher total, cardiovascular, and metabolic AL. Women possessed higher immune-related AL. For the total sample, age ranged from 25 to 90 years, 60 percent of respondents were female $(\mathrm{N}=627), 40$ percent were non-Hispanic White $(\mathrm{N}=426), 11$ percent were nonHispanic Black ( $\mathrm{N}=116), 37$ percent were US-born Mexican American $(\mathrm{N}=400)$, and 12 percent were foreign-born Mexicans ( $\mathrm{N}=130)$. Nearly 65 percent of the sample resided in Texas City for at least fifteen years with a larger proportion of men spending thirty or more years in the community, although this difference was not statistically significant. Mean distance from the plants was 1755 meters. Mean distance did not vary significantly by gender. The average CAPHRS score was 14 . Women had slightly higher concern (15) than men (14). Men reported more positive neighborhood perception (80, compared to 73 for women), fewer negative life events (just under 2, compared to over 2 for women), and fewer daily hassles (10, compared to 14 for women). Men in our sample were more likely to be 
older, married, earn higher income, smoke, exercise moderately, have health insurance, and report fewer health conditions.

In multivariate analyses predicting total AL (Table 3), Model 1 explained six percent of the variation (adjusted $R^{2}=.063$ ), Model 2 explained seven percent after adding stressors (adjusted $R^{2}=.071$ ), and Model 3 with controls explained 11 percent (adjusted $R^{2}=.108$ ). Comparing model fit for the full sample, stressors added little explanatory power and only marginally improved the fit of the model. For AL components in the total sample (Table 4), the full model explained the most variation in cardiovascular AL (adjusted $R^{2}=.131$ ). In the full sample predicting total AL, the daily hassles score was associated with $\mathrm{AL}$ in the predicted direction before controls were added (Table 3, Model 2, $\beta=.093, p=.012$ ). In Table 4 predicting AL components for the total sample, living in Texas City for more than 30 years was linked to higher cardiovascular AL (Table $4, \beta=.084, p=.028$ ) and more daily hassles predicted higher metabolic AL (Table $4, \beta=.088, p=.034$ ), net of all controls. Greater distance from the petrochemical plants was associated with lower immune-related AL ( $\beta=-$. $065, p=.046)$ and positive neighborhood perception was associated with lower metabolic AL $(\beta=-.080, p=.022)$.

In terms of basic gender differences, women had lower total AL (Table 3, Model 3, $\beta=-.120$, $p=<.001$; Table 4), cardiovascular AL, and metabolic AL, but higher immune-related AL. Yet, non-Hispanic Black women had higher cardiovascular and immune-related AL compared to non-Hispanic white women. Our ability to explain variation in AL and components differed by gender. Women's models explained more variation in allostatic load. Although Model 1 (Table 3) explained nine percent of variation in total AL for women (adjusted $R^{2}=.090$ ), Model 3 explained as much as 15 percent (adjusted $R^{2}=.145$ ). For men, Model 1 (Table 3) explained two percent of the variation in total AL (adjusted $R^{2}=.017$ ) and Model 3 explained five percent (adjusted $R^{2}=.048$ ). For women (Table 4), the model explained the largest amount of variance in cardiovascular AL (adjusted $R^{2}=.192$ ), followed by metabolic (adjusted $R^{2}=.076$ ), and then immune-related (adjusted $R^{2}=.055$ ). For men (Table 4), we see a different trend. The full model explained the largest amount of variation in men's metabolic AL (adjusted $R^{2}=.067$ ), followed by cardiovascular AL (adjusted $R^{2}=$. 036), then immune-related AL (adjusted $R^{2}=.031$ ).

Turning to the role of stressors and gender, greater geographic distance from the petrochemical plants was linked to lower total AL for women before controls were added (Table 3, Model 2, $\beta=-.096, p=.019$ ). More negative life events were associated with lower total AL for women in the final model (Model 3, $\beta=-.095, p=.027$ ). As with the full sample, however, adding stressors did not improve the overall fit of the model. Stressors did not significantly predict total AL for men in this sample. Examining components of AL (Table $4)$, residing in Texas City for more than 30 years predicting higher cardiovascular AL for women $(\beta=-.104, p=.031)$. Greater geographic distance from the petrochemical plants was associated with lower cardiovascular AL for women $(\beta=-.088, p=.031)$ and lower immunerelated AL for men $(\beta=-.107, p=.036)$. Finally, greater CAPHRS was linked to lower cardiovascular AL for men ( $\beta=-.136, p=.012)$. Because of the significant interaction between stressors and gender for cardiovascular AL (gender and residing in Texas City for more than 30 years; $\beta=.558, p=.020$ ), gender moderates the relationship between Texas City residence and cardiovascular AL. In other words, living in Texas City for more than 30 years was related to higher cardiovascular health risk for women but not men (Table 4). 


\section{Discussion}

\section{Stressors and Allostatic Load}

We found partial support for our first hypothesis that stressors predict higher AL. Four stressors were linked to elevated AL or AL components: long-term residence in Texas City, proximity to the petrochemical plants, poor neighborhood perception, and more daily hassles. These factors represent distinct processes. Texas City-related stressors are mechanisms of allostatic strain through their roles as environmental health threats. Not only do the plants produce smells, noise, and visible emissions, but residents are aware of a history of health risk and dangerous explosions, one of which occurred during data collection (Cutchin et al., 2008). ${ }^{1}$ Poor neighborhood perception is a less diffuse mechanism than Texas City-specific causes because neighborhood conditions are more immediately experienced by residents, regardless of location. Neighborhood perception also represents a social dimension of the environment (e.g., crime perception and social embeddedness). Daily hassles are more directly experienced, as they vary by individual more so than plant proximity and neighborhood perception. All four stressors can be considered chronic stressors that should be associated with AL, a process of dysregulation that occurs slowly over time (thus the associated term 'weathering'). Therefore, it is particularly noteworthy that although the linkages between chronic stressors and $\mathrm{AL}$ are not consistent across all models, they all predict some component of AL in our sample.

\section{Gender and Allostatic Load}

While the stress process literature discusses chronic, life-long stressors and AL, health disparities research may offer some insight into how chronic stressors may be captured in other variables such as gender. In support of our second hypothesis, there were gender differences in the explanatory power of our models and this effect varied by the type of AL outcome assessed. Our ability to predict AL through exposure to stressors was substantially greater for the sample of women compared to men. For men, very few of the variables examined offered insight into AL risk. Thus, not only are men in Texas City at risk due to their elevated AL, but we also know very little about the mechanisms that contribute to elevated AL for men. This insight reveals men's potential health risk. For women, we are able to pinpoint specific probable causes of elevated AL, such as long-term residence in Texas City or being non-Hispanic Black. Interactions between gender and race/ethnicity, however, were not statistically significant, indicating that race/ethnicity is not necessarily more important for women than it is for men. Further, men and women in our sample did not have significant descriptive differences in terms of Texas City-related stressors or racial/ ethnic composition. Rather, gender differences in our ability to predict AL may indicate that men and women manifest strain differently. This finding is consistent with health disparities literature, which notes that differential exposure to stressors is not necessarily linked to differences in actual stress and that health disparities should be evaluated using multiple health outcomes (McDonough and Walters, 2001; Turner and Avison, 2003). Future studies should continue to assess AL and AL components separately in order to assess a variety of physiological manifestations of stress for men and women.

\footnotetext{
${ }^{1}$ To ensure that exposure to the explosion did not bias results, the authors conducted sensitivity analyses for the subsample of individuals with full data on allostatic load components as well as full data on their experiences regarding the explosion $(\mathrm{N}=142)$. Although previous work found that exposure to this explosion was associated with poorer perceptions of health (Peek et al., 2008) and more concern about plant-related health risk (Cutchin et al., 2008), whether or not a respondent was exposed to the explosion did not affect allostatic load
} 


\section{Place Processes and Allostatic Load}

In addition to the direct effect of stressors and the explanatory power of stressors by gender, we found partial support for our final hypothesis that gender moderates the relationship between stressors and AL. Specifically, long-term residence in Texas City is significantly linked to higher cardiovascular risk for women only. This important gender difference allows us to explore an interesting new view of allostatic health risk through the concept of overlapping disadvantages, or "double jeopardy." Chronic stressors may influence AL through less obvious mechanisms, such as being a lifelong member of a disadvantaged group (e.g., being a woman) while experiencing prolonged exposure to an environmental riskscape (e.g., long-term residence in Texas City). The consequences of this enduring risk may be best understood when compared to the effects of shorter-term stressors.

Neighborhood perception and daily hassles, for example, were poor predictors of AL. In addition, concern about petrochemical health risk and negative life events were actually associated with lower AL. If we interpret these results as non-spurious, it may be that these measures reflect acute stressors, which are less likely to manifest as physiological risk (AL), compared to chronic stressors.

Because environmental riskscape exposure appears to have the most consistent relationship to elevated AL in our analysis, it implies that broader geographical processes shaping the Texas City riskscape are implicated in the story of allostatic load. By extending allostatic load theory and riskscape concepts, we are able to include broader and more historical processes of political power and territoriality. Risk exposure in the city as a whole (represented by years in the city) and in particular parts of the city (represented by distance to the plants and neighborhood conditions) have a role in understanding $\mathrm{AL}$ in the Texas City sample (Cutchin, 2007). By combining a consideration of chronic stressors and disadvantaged group membership in our analysis, along with the integrated perspectives of various geographical scales and processes, we are able, if only indirectly, to view the role of broader processes of inequality (e.g., global corporations, state apparatuses, and local agents) in enhanced AL risk in certain individuals. Moreover, the potential lesson learned is that it is not simply disadvantaged group membership that is related to AL. AL health risk is connected to broader powers that create risky urban environments, chronic stressors, unequal neighborhoods, and limited opportunities for particular groups.

Therefore, the concept of an environmental riskscape encompasses more than simply physical exposure to an environmentally-compromised space. Riskscapes themselves are inherently systems of 'double jeopardy,' as the individuals living within them are deeply intertwined in unequal geographical processes at multiple levels. This complex system of influences also creates additional inequalities such as the inability to relocate from environmental threats (Cutchin, 2007). Such inequalities, in turn, are accentuated for individuals who are members of more than one disadvantaged group (e.g., minority women). Overlapping sources of jeopardy may become too much to cope with, especially without the resources or the power to counter the underlying macro-level causes of inequality. Although sensitivity tests of race/ethnicity interactions indicate that the effects of gender and stressors do not differ significantly by race/ethnicity in Texas City, minority women residing in other environmental riskscapes may be at risk for 'triple jeopardy' and thus vulnerable to poor health outcomes such as elevated AL. Indeed, studies in the US have found extensive evidence of the health risks associated with racial/ethnic spatial inequality (Massey, 2004; Williams and Collins, 2001), particularly in environmental riskscapes (Hipp and Lakon, 2010; Pastor et al., 2005). Therefore, the role of race/ethnicity in the broader story of stressors, gender, and allostatic load deserves continued attention in future work exploring health disparities in environmental riskscapes. 
Before concluding this study, we first review a few limitations. First, these data are crosssectional. In the absence of longitudinal data, we are conservative in our discussion of causality. Second, although the environmentally-compromised nature of Texas City allows us to explore the concept of riskscapes, the dataset is not nationally representative and thus our ability to generalize findings to other locales is limited. Finally, we did not examine neuroendocrine components of AL in our analysis so the results of this study cannot be directly compared to Seeman et al.'s (2002) study of gender and AL.

\section{Conclusion}

Despite limitations, this study is the first known examination of stressors, gender, and AL within an environmental riskscape and thus provides important contributions. First, our analysis provides one of the most comprehensive tests of stressors and AL by exploring a range of chronic and acute stressors through diverse measures such as exposure to environmental threat, subjective assessments of risk and neighborhoods, and daily hassles/ negative life events. Second, although most studies of AL immediately stratify samples by gender without theoretically or empirically addressing the role of gender in health risk, our study specifically outlines a theoretical argument for gendered health disparities and offers an empirical test of the direct and moderating influences of gender. Finally, this study examines allostatic load within the context of an environmental riskscape and proposes a model in which geopolitical mechanisms intertwine to create a landscape where disadvantaged individuals experience heightened health risk (allostatic load).

In conclusion, our study suggests that chronic stressors, such as residential proximity to petrochemical plants, prolonged residence in Texas City, negative neighborhood perception, and daily hassles may be linked to elevated AL or AL components. Although women in our sample were exposed to more chronic stressors, they fared better than men in terms of AL. Women, however, are at cardiovascular risk for 'double jeopardy' when living in an environmentally-compromised landscape for a prolonged period of time while men are not. This combination of chronic stressor and gender considerations is a potential new direction for future research on stress, AL, and health disparities. Furthermore, our findings should be interpreted in the wider context of geographical processes theorized to be related to the creation of environmental riskscapes and to AL. Knowledge of disparities and increased risk is not sufficient to understand ultimate causes of allostatic load. Rather, it is essential to look across geographical scales at processes that shape risk and eventually the physiological response to stress from risk. By considering stressors, gender, and AL in the framework of a riskscape, we develop a more integrative understanding about how place is central to health.

\section{Acknowledgments}

The authors wish to thank James S. Goodwin and two anonymous reviewers for their helpful comments and suggestions. This work was supported by Grant P50 CA10563 from the National Cancer Institute which funded the UTMB Center for Population Health and Health Disparities as well as the Texas City Stress and Health Study.

\section{References}

Aneshensel CS, Rutter CM, Lachenbruch PA. Social-structure, stress, and mental-health: Competing conceptual and analytic models. American Sociological Review. 1991; 56:166-178.

Burby RJ, Strong DE. Coping with chemicals: Blacks, Whites, planners, and industrial pollution. Journal of the American Planning Association. 1997; 63:469-480.

Clark MS, Bond MJ, Hecker JR. Environmental stress, psychological stress and allostatic load. Psychology, Health \& Medicine. 2007; 12:18-30. 
Cohen, S.; Williamson, G. Perceived Stress in a Probability Sample of the US. In: Spacapam, S.; Oskamp, S., editors. The Social Psychology of Health: Claremont Symposium on Applied Social Psychology. Sage; Newbury Park: 1988. p. 31-67.

Crimmins EM, Johnston M, Hayward M, Seeman T. Age differences in allostatic load: an index of physiological dysregulation. Experimental Gerontology. 2003; 38:731-734. [PubMed: 12855278]

Crimmins EM, Kim JK, Alley DE, Karlamangla A, Seeman T. Hispanic paradox in biological risk profiles. American Journal of Public Health. 2007; 97:1305-1310. [PubMed: 17538054]

Cutchin MP. The need for the "new health geography" in epidemiologic studies of environment and health. Health \& Place. 2007; 13:725-742. [PubMed: 17208033]

Cutchin MP, Martin KR, Owen SV, Goodwin JS. Concerns about petrochemical health risk before and after a refinery explosion. Risk Analysis. 2008; 28:589-601. [PubMed: 18643817]

Dowd JB, Simanek AM, Aiello AE. Socio-economic status, cortisol and allostatic load: a review of the literature. International Journal of Epidemiology. 2009; 38:1297-1309. [PubMed: 19720725]

Evans GW. A multimethodological analysis of cumulative risk and allostatic load among rural children. Developmental Psychology. 2003; 39:924-933. [PubMed: 12952404]

Ganzel BL, Morris PA, Wethington E. Allostasis and the human brain: Integrating models of stress from the social and life sciences. Psychological Review. 2010; 117:134-174. [PubMed: 20063966]

Garson, GD. Data Imputation for Missing Values. Statnotes: Topics in Multivariate Analysis. 2008. Retrieved 1 March 2010, from http://faculty.chass.ncsu.edu/garson/pa765/statnote.htm

Geronimus AT, Hicken M, Keene D, Bound J. "Weathering” and age patterns of allostatic load scores among blacks and whites in the United States. American Journal of Public Health. 2006; 96:826833. [PubMed: 16380565]

Glei DA, Goldman N, Chuang YL, Weinstein M. Do chronic stressors lead to physiological dysregulation? Testing the theory of allostatic load. Psychosomatic Medicine. 2007; 69:769-776. [PubMed: 17942833]

Greenberg MR, Schneider DF. Gender differences in risk perception: Effects differ in stressed vs. nonstressed environments. Risk Analysis. 1995; 15:503-511. [PubMed: 7480950]

Hallman WK, Wandersman AH. Attribution of responsibility and individual and collective coping with environmental threats. Journal of Social Issues. 1992; 48:101-118.

Hill TD, Burdette AM, Hale L. Neighborhood disorder, sleep quality, and psychological distress: Testing a model of structural amplification. Health \& Place. 2009; 15:1006-1013. [PubMed: 19447667]

Hipp JR, Lakon CM. Social disparities in health: Disproportionate toxicity proximity in minority communities over a decade. Health \& Place. 2010; 16:674-683. [PubMed: 20227324]

Kaestner R, Pearson JA, Keene D, Geronimus AT. Stress, allostatic load, and health of Mexican immigrants. Social Science Quarterly. 2009; 90:1089-1111. [PubMed: 21165158]

Kanner AD, Coyne JC, Schaefer C, Lazarus RS. Comparison of two modes of stress measurement: Daily hassles and uplifts versus major life events. Journal of Behavioral Medicine. 1981; 4:1-39. [PubMed: 7288876]

Lau G, Hui KK, Lam SK. Life events and daily hassles in patients with atypical chest pain. American Journal of Gastroenterology. 1996; 91:2157-2162. [PubMed: 8855740]

Lazarus, RS. Emotion and Adaptation. Oxford: Oxford University Press; 1991.

Lazarus, RS. Stress and Emotion: A New Synthesis. New York: Springer Publishing; 1999.

Loucks EB, Juster RP, Pruessner JC. Neuroendocrine biomarkers, allostatic load, and the challenge of measurement: A commentary on Gersten. Social Science \& Medicine. 2008; 66:525-530.

Luginaah IN, Taylor SM, Elliott SJ, Eyles JD. A longitudinal study of the health impacts of a petroleum refinery. Social Science \& Medicine. 2000; 50:1155-1166. [PubMed: 10714934]

Macintyre S, Hunt K, Sweeting H. Gender differences in health: Are things really as simple as they seem? Social Science \& Medicine. 1996; 42:617-624. [PubMed: 8643986]

Martinez ML, Black M, Starr RH. Factorial structure of the Perceived Neighborhood Scale (PNS): A test of longitudinal invariance. Journal of Community Psychology. 2002; 30:23-43.

Massey DS. Segregation and stratification: A biosocial perspective. Du Bois Review. 2004; 1:7-25. 
McKinnon W, Weisse CS, Reynolds CP, Bowles CA, Baum A. Chronic stress, leukocyte subpopulations, and humoral response to latent viruses. Health Psychology. 1989; 8:389-402. [PubMed: 2555149]

McDonough P, Walters V. Gender and health: reassessing patterns and explanations. Social Science \& Medicine. 2001; 52:547-559. [PubMed: 11206652]

McEwen BS. Protective and damaging effects of stress mediators. New England Journal of Medicine. 1998; 338:171-179. [PubMed: 9428819]

McEwen BS, Seeman T. Protective and damaging effects of mediators of stress - Elaborating and testing the concepts of allostasis and allostatic load. Annals of the New York Academy of Sciences. 1999; 896:30-47. [PubMed: 10681886]

Meyler D, Stimpson JP, Cutchin MP. Landscapes of risk - Texas City and the petrochemical industry. Organization \& Environment. 2007; 20:204-212.

Morello-Frosch R, Shenassa ED. The environmental "Riskscape" and social inequality: Implications for explaining maternal and child health disparities. Environmental Health Perspectives. 2006; 114:1150-1153. [PubMed: 16882517]

Newsom JT, Prigerson HG, Schulz R, Reynolds CF. Investigating moderator hypotheses in aging research: Statistical, methodological, and conceptual difficulties with comparing separate regressions. International Journal of Aging \& Human Development. 2003; 57:119-150. [PubMed: 15151187]

Pastor M, Morello-Frosch R, Sadd JL. The air is always cleaner on the other side: Race, space, and ambient air toxics exposures in California. Journal of Urban Affairs. 2005; 27:127-148.

Pearlin LI, Schieman S, Fazio EM, Meersman SC. Stress, health, and the life course: Some conceptual perspectives. Journal of Health and Social Behavior. 2005; 46:205-219. [PubMed: 16028458]

Peek MK, Cutchin MP, Freeman DH, Perez NA, Goodwin JS. Perceived health change in the aftermath of a petrochemical accident: an examination of pre-accident, within-accident, and postaccident variables. Journal of Epidemiology and Community Health. 2008; 62:106-112. [PubMed: 18192597]

Peek MK, Cutchin MP, Freeman D, Stowe RP, Goodwin JS. Environmental hazards and stress: evidence from the Texas City Stress and Health Study. Journal of Epidemiology and Community Health. 2009a; 63:792-798. [PubMed: 19282316]

Peek MK, Cutchin MP, Salinas JJ, Sheffield KM, Eschbach K, Stowe RP, Goodwin JS. Allostatic load among non-Hispanic whites, non-Hispanic blacks, and people of Mexican origin: Effects of ethnicity, nativity, and acculturation. American Journal of Public Health. 2009b; 99:1-7.

Peters ML, Godaert GLR, Ballieux RE, Heijnen CJ. Moderation of physiological stress responses by personality traits and daily hassles: less flexibility of immune system responses. Biological Psychology. 2003; 65:21-48. [PubMed: 14638287]

Rieker PP, Bird CE. Rethinking gender differences in health: Why we need to integrate social and biological perspectives. Journals of Gerontology Series B-Psychological Sciences and Social Sciences. 2005; 60:40-47.

Seeman TE, Singer BH, Rowe JW, Horwitz RI, McEwen BS. Price of adaptation - Allostatic load and its health consequences - MacArthur studies of successful aging. Archives of Internal Medicine. 1997; 157:2259-2268. [PubMed: 9343003]

Seeman TE, Singer BH, Ryff CD, Love GD, Levy-Storms L. Social relationships, gender, and allostatic load across two age cohorts. Psychosomatic Medicine. 2002; 64:395-406. [PubMed: 12021414]

Seeman TE, McEwen B, Rowe J, Singer BH. Allostatic load as a marker of cumulative biological risk: MacArthur studies of successful aging. Proceedings of the National Academy of Science. 2001; 98:4770-4775.

Sherbourne CD, Stewart AL. The MOS Social Support Survey. Social Science \& Medicine. 1991; 32:705-714. [PubMed: 2035047]

Simandan D. On how much one can take: relocating exploitation and exclusion within the broader framework of allostatic load theory. Health \& Place. 2010; 16:1291-1293. [PubMed: 20813575] 
Sterling, P.; Eyer, J. Allostasis: A new paradigm to explain arousal pathology. In: Fisher, S.; Reason, J., editors. Handbook of Life Stress, Cognition and Health. John Wiley \& Sons; New York: 1998. p. 629-649.

Stowe RP, Mehta SK, Ferrando AA, Feeback DL, Pierson DL. Immune responses and latent herpesvirus reactivation in spaceflight. Aviation, Space, and Environmental Medicine. 2001; 72:884-891.

Stowe RP, Peek MK, Cutchin MP, Goodwin JS. Plasma cytokine levels in a population-based study: Relation to age and ethnicity. Journals of Gerontology Series a-Biological Sciences and Medical Sciences. 2010a; 65:429-433.

Stowe RP, Peek MK, Perez NA, Yetman DL, Cutchin MP, Goodwin JS. Herpesvirus reactivation and socioeconomic position: A community-based study. Journal of Epidemiology and Community Health. 2010b; 64:666-671. [PubMed: 19825788]

Stronegger WJ, Titze S, Oja P. Perceived characteristics of the neighborhood and its association with physical activity behavior and self-rated health. Health \& Place. 2010; 16:736-743. [PubMed: 20378392]

Taylor SE, Repetti RL, Seeman T. Health psychology: What is an unhealthy environment and how does it get under the skin? Annual Review of Psychology. 1997; 48:411-447.

Tingate TR, Desmond JL, Muller HK, Stowe RP, Pierson DL. Antarctic isolation: immune and viral studies. Immunology and Cell Biology. 1997; 75:275-283. [PubMed: 9243293]

Turner RJ, Avison WR. Status variations in stress exposure: Implications for the interpretation of research on race, socioeconomic status, and gender. Journal of Health and Social Behavior. 2003; 44:488-505. [PubMed: 15038145]

Turner RJ, Wheaton B, Lloyd DA. The epidemiology of social stress. American Sociological Review. 1995; 60:104-125.

Williams DR, Collins C. Racial residential segregation: A fundamental cause of racial disparities in health. Public Health Reports. 2001; 116:404-416. [PubMed: 12042604]

Williams R, Zyzanski SJ, Wright AL. Life events and daily hassles and uplifts as predictors of hospitalization and outpatient visitation. Social Science \& Medicine. 1992; 34:763-768. [PubMed: 1604370]

Yang TC, Matthews SA. The role of social and built environments in predicting self-rated stress: A multilevel analysis in Philadelphia. Health \& Place. 2010; 16:803-810. [PubMed: 20434389] 


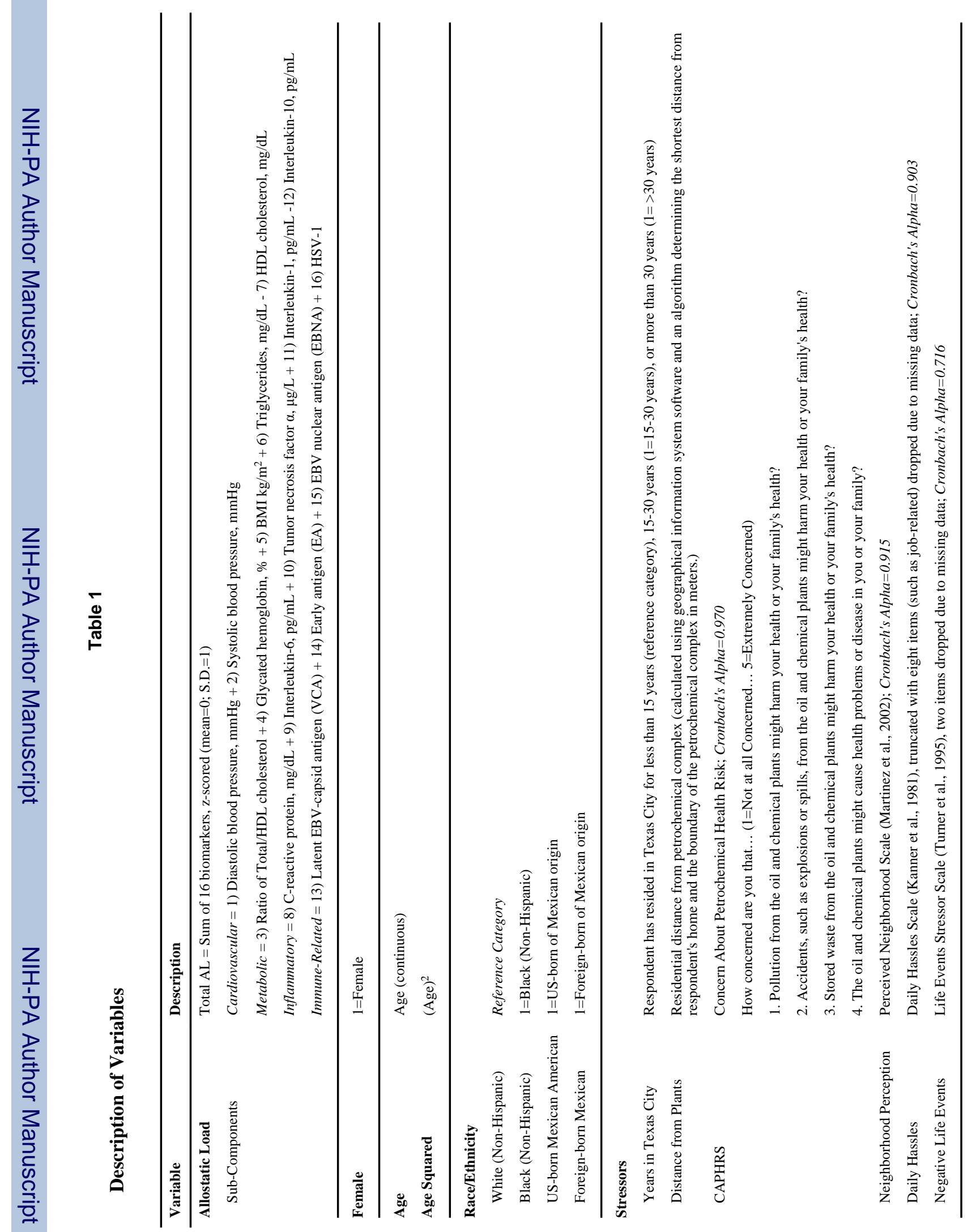




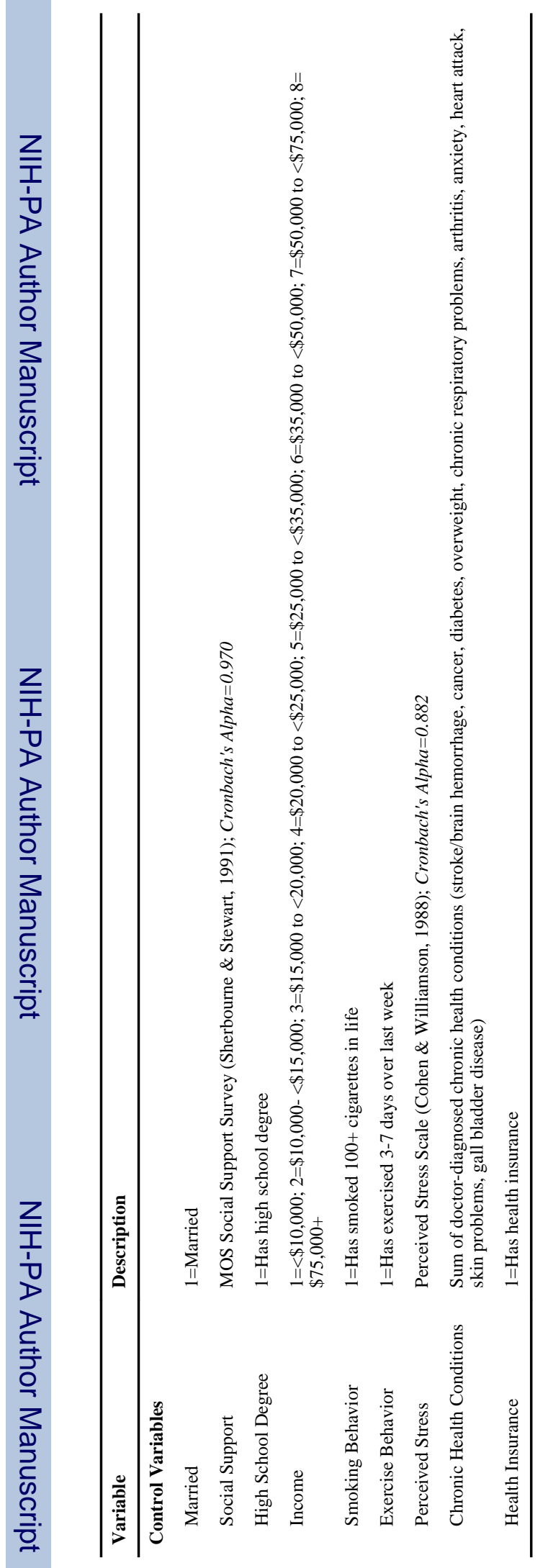

Health Place. Author manuscript; available in PMC 2012 July 1. 


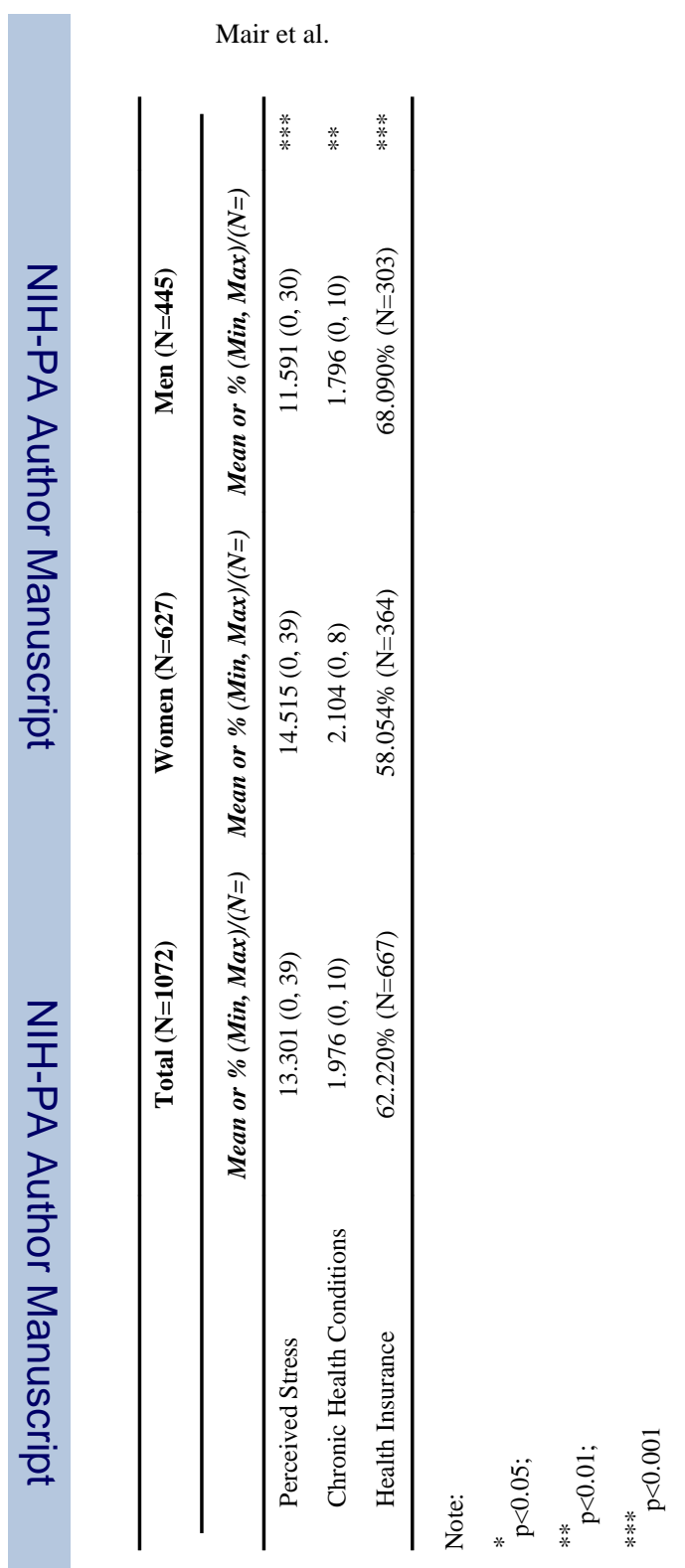

Page 17 


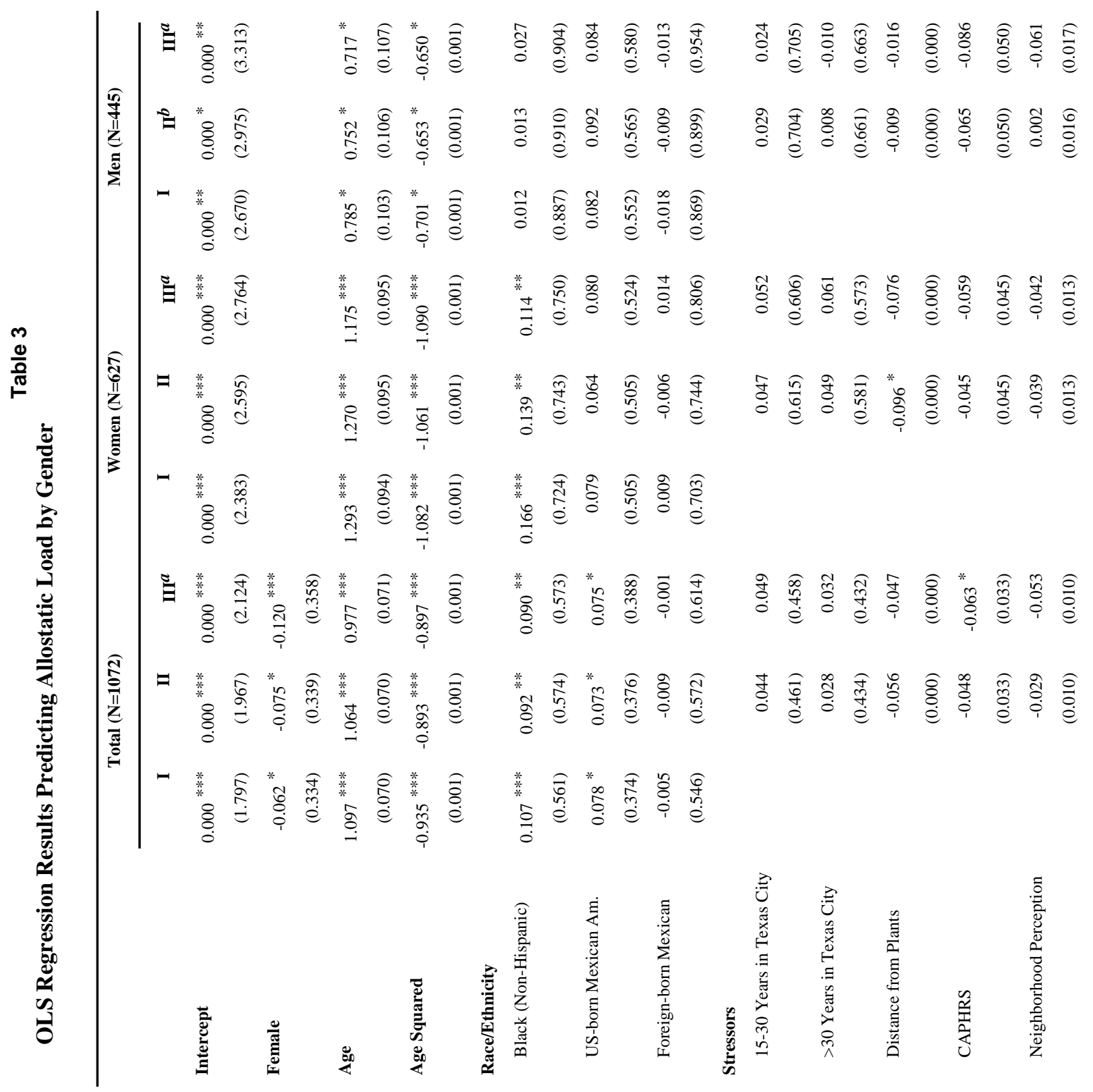




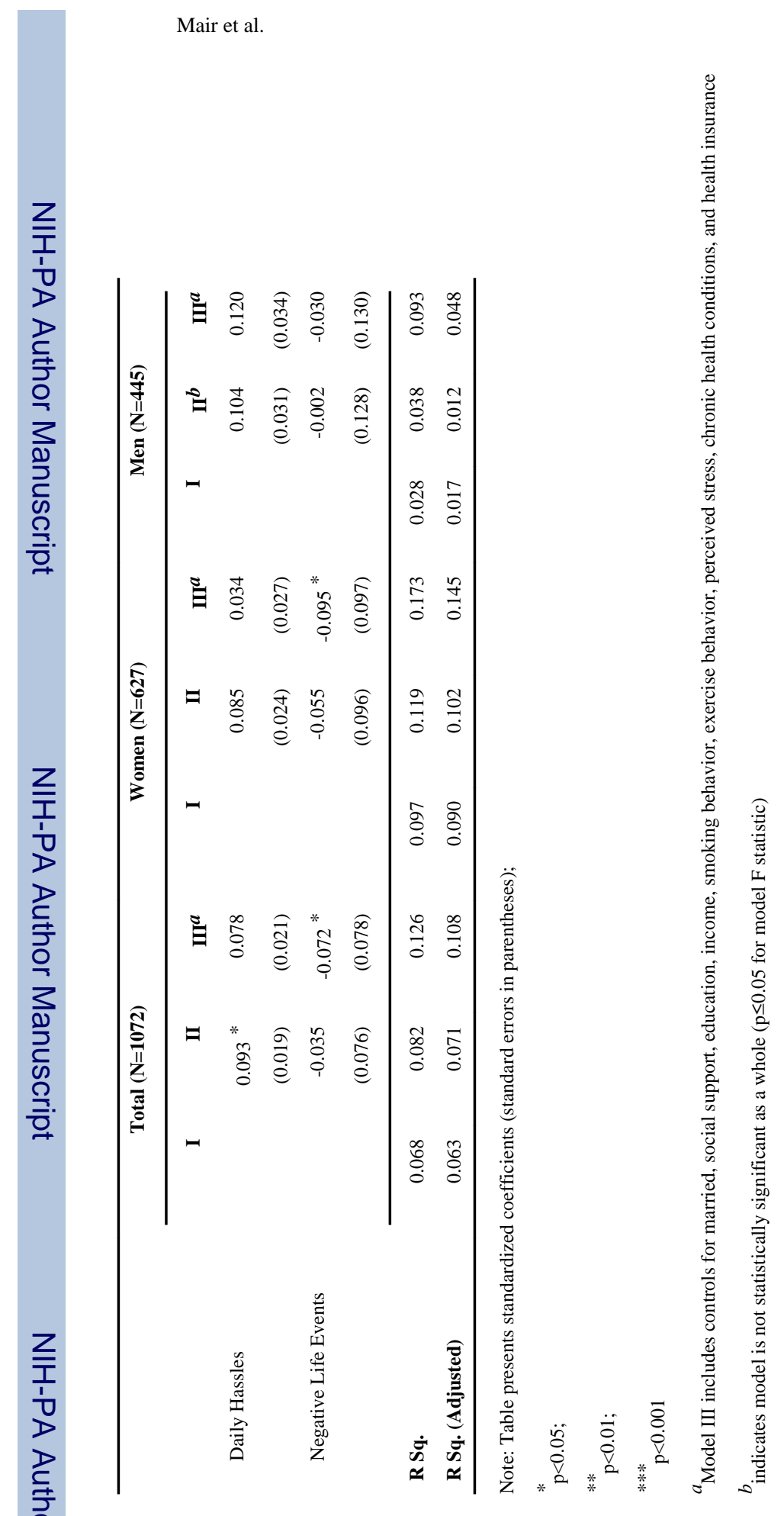

Health Place. Author manuscript; available in PMC 2012 July 1. 


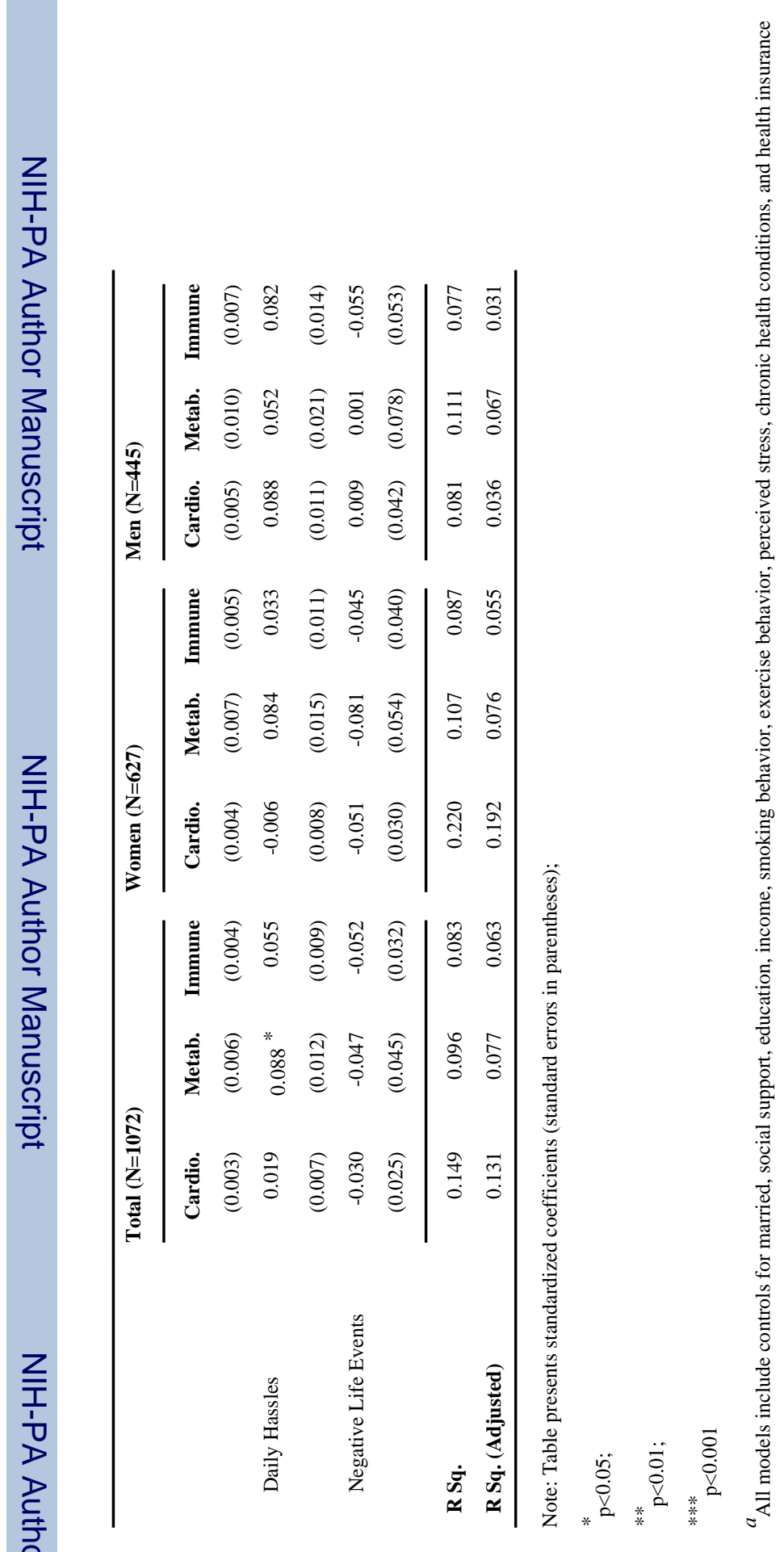

Health Place. Author manuscript; available in PMC 2012 July 1. 